\title{
ISOLATION OF A CDNA \\ ENCODING AN IGG IMMUNOREACTIVE ANTIGEN (ZINC FINGER PROTEIN) OF STRONGYLOIDES STERCORALIS
}

\author{
SIDDIQUI A.A.*, STANLEY C.S.* \& BERK S.L.*
}

\section{Summary :}

A full length cDNA encoding an lgG immunoreactive antigen of Strongyloides stercoralis is described. A clone containing 1,328 bp insert was selected following screening of $S$. stercoralis CDNA library with an $\lg G$ fraction obtained from a pool of 78 S. stercoralis positive human sera samples. The nucleotide sequence of the 1,328 bp insert was found to be $70.5 \% \mathrm{~A} / \mathrm{T}$, reflecting a characteristic $A / T$ codon bias of $S$. stercoralis. The nucleotide sequence of this insert identified a cDNA coding for a zinc finger protein. The conceptually translated amino acid sequence of the open reading frame for the $\lg G$ immunoreactive antigen of $S$. stercoralis encodes a 211 amino acid residue protein with an apparent molecular weight of $22.8 \mathrm{kDa}$ and a predicted isoelectric point of 8.71 . The diagnostic potential of this $\lg G$ immunoreactive antigen of $S$. stercoralis is also discussed.

KEY WORDS : Strongyloides, parasite, antigen
Résumé : ISOLEMENT D'UN ADNC CODANT POUR UN ANTIGÈNE (PROTÉINE EN DOIGT DE ZINC) DE STRONGYLOIDES STERCORALIS RÉAGISSANT AVEC DES ANTICORPS IGG

La totalité de I'ADNC codant pour un antigène de Strongyloides stercoralis réagissant avec des anticorps lgG est décrite. Un clone représentant 1328 bp a été sélectionné à la suite de l'étude d'une banque d'ADNc de Strongyloides stercoralis à l'aide d'un pool de 78 sérums humains positifs à $\mathrm{S}$. stercoralis. La séquence nucléotidique des 1328 paires de bases est de 70,5\% A/T reflétant le biais caractéristique de $\mathrm{S}$. stercoralis vers l'usage de codons riches en $A / T$. La séquence nucléotidique de cet ADNc révèle une homologie avec celles codant pour des protéines en doigt de zinc. La séquence en acides aminés qui a été déduite pour cet antigène caractérise une protéine de 211 acides aminés, d'une masse molaire apparente de 22,8 kDa ayant un point isoélectrique prévu de 8,71. L'utilisation potentielle de cet antigène pour le diagnostic de S. stercoralis est discuté dans la partie finale.

MOTS CLÉS : Strongiloides, parasite, antigène.
S trongyloides stercoralis is endemic in tropical and subtropical areas worldwide and in the southeastern United States (for review see, Berk et al., 1987; Liu \& Weller, 1993; Grove 1996; Zaha et al., 2000). S. stercoralis has unique characteristics, including its ability to replicate in the human host. This ability permits cycles of autoinfection, and a disposition to produce chronic disease. (Grove 1996; Mansfield et al., 1996). Categorization of infection includes acute, chronicuncomplicated, and disseminated forms (Wehner \& Kirsch, 1997). Clinical manifestations depend on the particular organs involved, $15-30 \%$ of chronically infected people harbor asymptomatic gut infections (Wehner \& Kirsch, 1997). On the other hand, in patients on chronic steroid therapy, hyperinfection can develop with the dissemination of larvae

\footnotetext{
* Department of Internal Medicine, Texas Tech University Health Sciences Center, Amarillo VA Heath Care System, Amarillo, Texas 79106, USA.

Correspondence: Afzal A. Siddiqui, Department of Internal Medicine, Texas Tech University Health Sciences Center, 1400 Wallace Blvd. Amarillo, Texas 79106, USA

Tel: (806) 354-5524 - Fax: (806) 354-5764

E-mail: siddiqui@cortex.ama.ttuhsc.edu
}

to extra-intestinal organs which results in mortality rates of up to $80 \%$ (for review see, Woodring et al., 1996; Siddiqui et al., 2000a,b,c). The diagnosis of S. stercoralis infection is suspected in patients from endemic areas who have blood eosinophilia, and gastrointestinal or pulmonary symptoms (for review see, Liu \& Weller, 1993; Wehner \& Kirsch, 1997). A definitive diagnosis is established by demonstration of $S$. stercoralis larvae in stool, body fluids, or tissues (for review see, Liu \& Weller, 1993; Wehner \& Kirsch, 1997). A presumptive diagnosis of $S$. stercoralis infection can be achieved by serology.

The ELISA for the detection of serum IgG against crude extract of filariform larvae can be $85 \%$ sensitive in detecting $S$. stercoralis infection (Neva et al., 1981). However, the specificity of this ELISA is limited (Conway et al., 1994; Siddiqui et al., 1997). Therefore identification of bona fide $S$. stercoralis antigens is essential for the development of a sensitive and specific diagnostic test.

Following is a report on the isolation of a cDNA clone encoding a $S$. stercoralis antigen (zinc finger protein) which is recognized by the host's immune system in natural human infections. This antigen may have some diagnostic potential. 


\section{MATERIALS AND METHODS}

\section{SERA AND ANTIBODY PURIFICATION}

S eventy eight different sera samples were obtained TN (Siddiqui et al., 1997). All of these patients had a significant number of Strongyloides larvae in their stool samples and were diagnosed with only $S$. stercoralis infection. The serology and parasite ova examinations of these 78 patients were negative for other parasites (Siddiqui et al., 1997). These 78 sera samples from only Strongyloides-infected patients were pooled and presoaked with tissues homogenates of schistosomes, filarial parasites, hookworms and Onchocerca. The precleared sera was used to isolate an IgG fraction via affinity chromatography using immobilized Protein A in a hydrophilic matrix, Trisacryl GF2000 (Pierce, Rockford, IL). This IgG fraction was used to screen a directional S. stercoralis cDNA library.

\section{CDNA LIBRARY CONSTRUCTION AND SCREENING}

A cDNA library was constructed as follows: doublestranded, size-selected $(>0.4 \mathrm{~kb})$, high molecular weight cDNA was prepared using oligo-dT primed $S$. stercoralis mRNA ( $\mathrm{L}_{3}$ larvae) which was isolated using magnetic beads (Dynal, Lake Success, NY). The cDNA ends were modified by ligation of linkers enco- ding EcoRI and XhoI sites and then cloned into compatible sites present in the multiple cloning region of the Uni-ZAP XR vector (Stratagene, La Jolla, CA). $S$. stercoralis $\mathrm{CDNA}$ expression library was screened with the IgG fraction as described earlier (Karcz et al., 1991; Siddiqui et al., 2000b). Primary screening yielded several positive clones, one such clone (16B-4) containing a $1.3 \mathrm{~kb}$ insert was selected because of its very high immunoreactivity. This clone was plaque-purified and subcloned into pBluescript. The $1.3 \mathrm{kB}$ insert was sequenced using T3 and T7 primers at the Molecular Genetics Facility, Athens, GA.

\section{SEQUENCE ANALYSIS}

The sequence was then compared with the GenBank database by BLAST analysis (Altschul et al., 1997). The $1.3 \mathrm{kB}$ insert contained the full-length cDNA for a zinc finger protein of $S$. stercoralis designated SsZFP. The SsZFP sequence has been deposited in GenBank (Accession \# AF188206). Multiple sequence alignment of SsZFP with other sequences was performed via MULTALIN software (Corpet 1988).

\section{RESUITS AND DISCUSSION}

n our continual effort to improve the diagnosis of $S$. stercoralis we report the cloning of an immunoreactive antigen which may play a role in the deve-

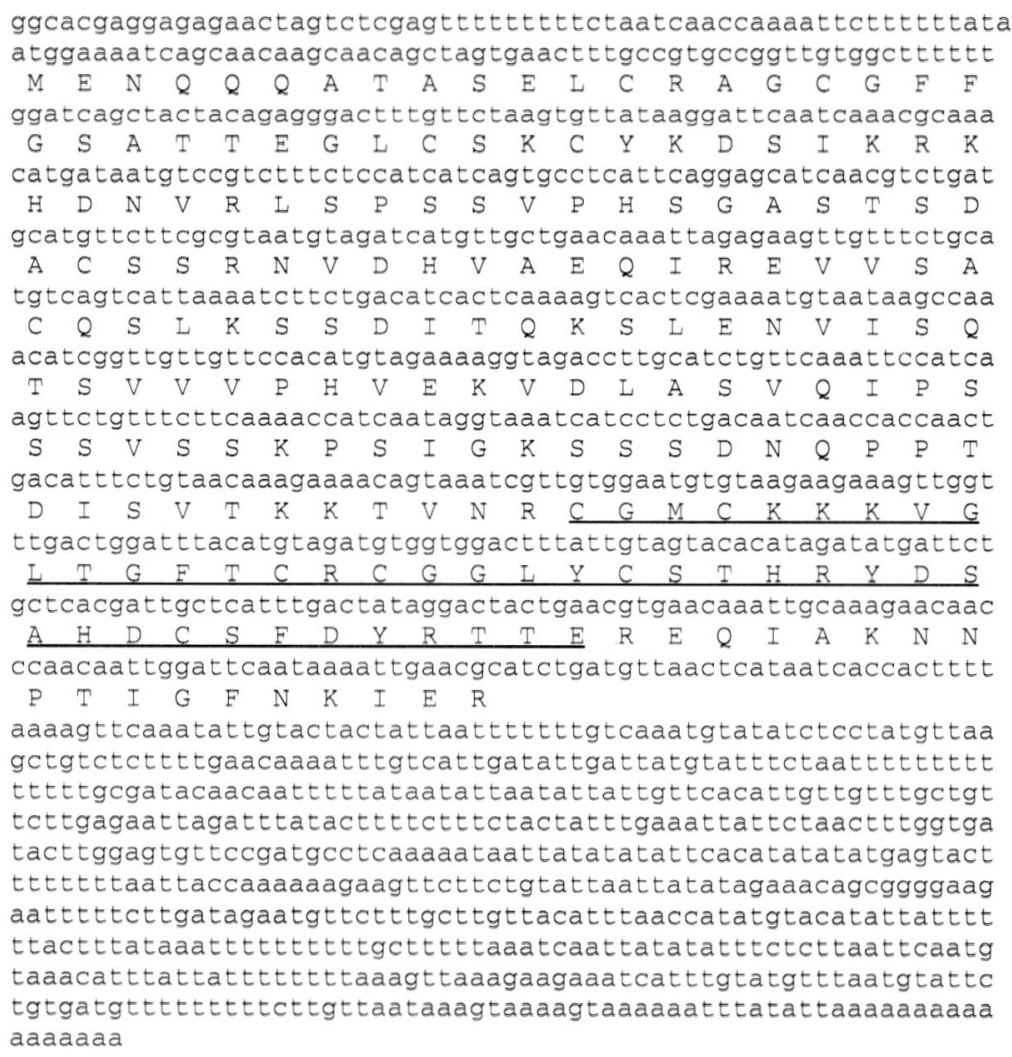

Fig. 1. - Nucleotide and deduced amino acid sequence of the CDNA encoding a Strongyloides stercoralis zinc finger protein. Zinc finger domain AN1 is underlined (amino residues 152-192). 
lopment of a serodiagnostic test. To obtain a cDNA clone for this antigen, we have first obtained an $\operatorname{IgG}$ fraction from a pool of 78 sera samples obtained from patients with $S$. stercoralis infection (Siddiqui et al., 1997). The screening of $S$. stercoralis cDNA library with this IgG fraction yielded numerous clones. However, one positive clone (16B-4) showed very high immunoreactivity. This clone was selected and an insert of $1.3 \mathrm{kB}$ was obtained following $E c o R I$ and $X b o$ I digestion. The nucleotide sequencing of this insert is shown in Figure 1. The search of GenBank identified this IgG immunoreactive antigen to be a zinc finger protein (Altschul et al., 1997).

An open reading frame for SsZFP potentially encodes a 211 amino acid residue protein with an apparent molecular weight of $22.8 \mathrm{kDa}$ and an isoelectric point of 8.71 . The SsZFP sequence contains a typical poly (A) addition site (AATAAA) 22 bases upstream of poly (A) tail that is composed of 17 bases. Further, SsZFP sequence has a characteristic $\mathrm{A} / \mathrm{T}$ bias (Moore et al., 1996; Siddiqui et al., 2000a,b,c), and is $70.5 \% \mathrm{~A} / \mathrm{T}$. The full length sequence of SsZFP exhibits $42 \%$ identity in amino acid composition with Caenorbabditis elegans zinc finger protein (Z71262). SsZFP also showed $32 \%$ identity in amino acid sequence with mouse (AF062071) and human (PZNF216) zinc finger protein ZNF 216 (Fig. 2). The comparison of SsZFP sequence and those of free-living nematode (C. elegans), mouse and human zinc finger protein ZNF 216 suggest that all share a common ancestry (Fig. 2). The ZNF216 gene is highly conserved between human and mouse, contains two regions that show homology to the putative zinc finger domains of other proteins, and may be involved in autosomal recessive nonsyndromic hearing loss (Scott et al., 1998). However, the function of SsZFP is yet to be elucidated.

Protein Families Data Base of Alignments and Hidden Markov Models (Pfam HMM) search revealed, SsZFP amino acid sequence contains a AN1-like (Linnen et al., 1993) zinc finger at the C-terminus from amino residues 152-192 (Fig. 1). Seven distinct ABlock Motifs were also detected in the SsZFP sequence. More importantly, Transfac search (Quandt et al., 1995) of the SsZFP nucleotide sequence showed the presence of four (nucleotides, 191-180, 450-461, 201B212, and 260271) consensus sequences (NWWWATCATNNN) of C. elegans skn-1 motif, a maternal gene product (Blackwell et al., 1994). In C. elegans, skn1 is usually required for embryonic endodermal and mesodermal specification and for maintaining differentiated intestinal cells postembryonically (Walker et al., 2000), its role is $S$. stercoarlis is yet to be elucidated. Furthermore, The prediction for SsZFP according to the neural networks method for cytoplasmic/nuclear discrimination was found to be nuclear with $94 \%$ reliability (Reinhardt \& Hubbard, 1998).

Several immunodiagnostic assays for the detection of S. stercoralis have been tested over the years with

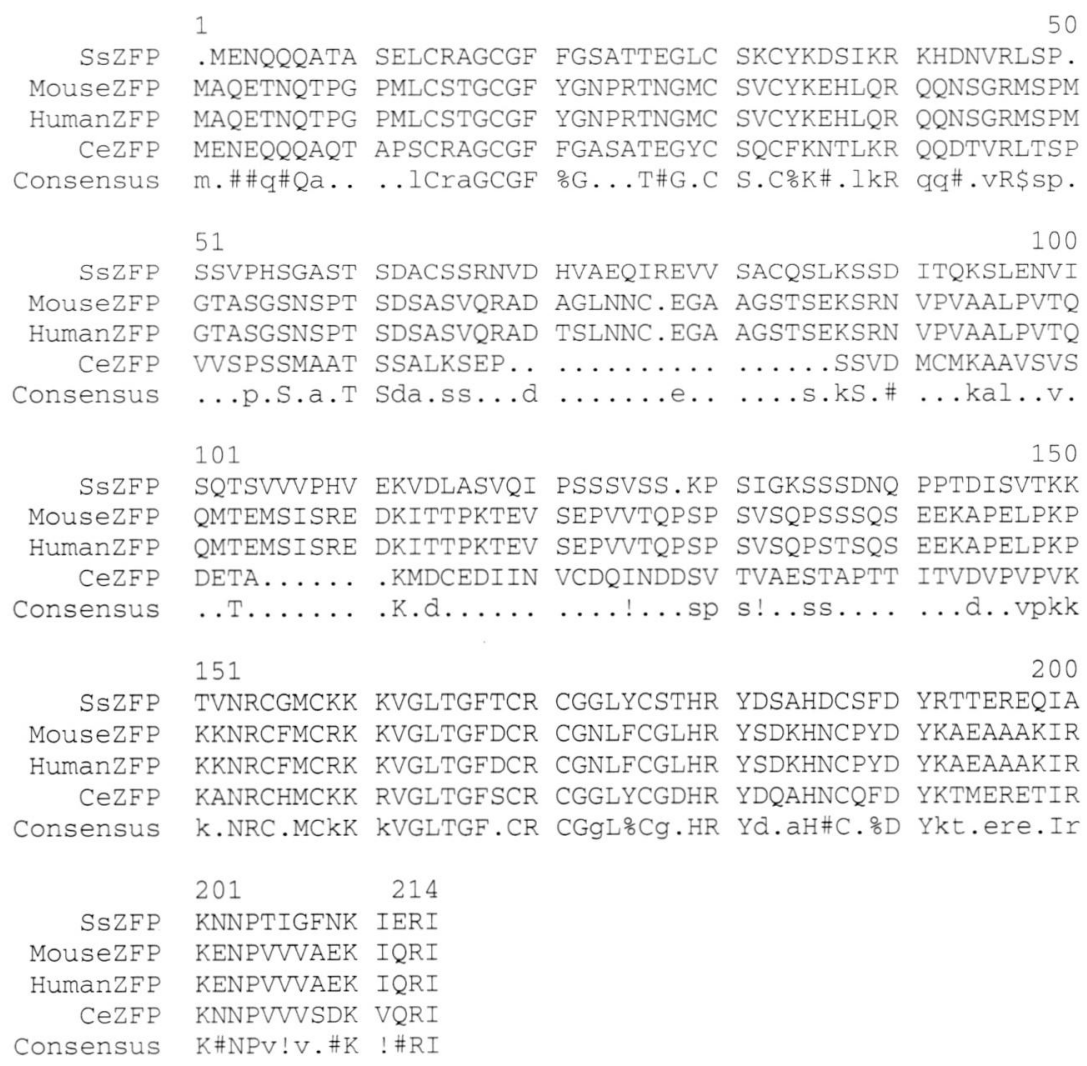

SSZFP

MouseZFP

HumanZFP

CezFP

Consensus

SSZFP

MousezFP

HumanZFP

CeZFP

Consensus

SSZFP

MouseZFP

HumanzFP

CEZFP

Consensus

SSZFP

MouseZFP

HumanZFP

CezfP

Consensus

$$
\begin{array}{r}
\text { SsZFP } \\
\text { MousezFP } \\
\text { HumanzFP } \\
\text { CeZFP } \\
\text { Consensus }
\end{array}
$$

1

MENQQQATA SELCRAGCGF FGSATTEGLC SKCYKDSIKR KHDNVRLSP. MAQETNQTPG PMLCSTGCGF YGNPRTNGMC SVCYKEHLQR QQNSGRMSPM MAQETNQTPG PMLCSTGCGF YGNPRTNGMC SVCYKEHLQR QQNSGRMSPM MENEQQQAQT APSCRAGCGF FGASATEGYC SQCFKNTLKR QQDTVRLTSP m.\#\#q\#Qa. . . ICraGCGF \%G...T\#G.C S.C\%K\#.IkR qq\#.vR\$sp.

51

SSUPHSGAST SDACSGRNVD HUAEQTREVV SACQSTHSSD ITQKSLE GTASGSNSPT SDSASVQRAD AGLNNC.EGA AGSTSEKSRN VPVAALPVTO GTASGSNSPT SDSASVQRAD TSLNNC.EGA AGSTSEKSRN VPVAALPVTQ VVSPSSMAAT SSALKSEP. . . . . . . . . . SSVD MCMKAAVSVS ..p.s.a.T sda.ss...d ......e......s.ks.\# ...kal..v.

101

150

SQTSVVVPHV EKVDLASVQI PSSSVSS.KP SIGKSSSDNQ PPTDISVTKK QMTEMSISRE DKITTPKTEV SEPVVTQPSP SVSQPSSSQS EEKAPELPKP QMTEMSISRE DKITTPKTEV SEPVVTQPSP SVSQPSTSQS EEKAPELPKP DETA....... KMDCEDIIN VCDQINDDSV TVAESTAPTT ITVDVPVPVK .T...................sp s!.ss........vpkk 151

TVNRCGMCKK KVGLTGFTCR CGGLYCSTHR YDSAHDCSFD YRTTEREQIA KKNRCFMCRK KVGLTGFDCR CGNLFCGLHR YSDKHNCPYD YKAEAAAKIR KKNRCFMCRK KVGLTGFDCR CGNLFCGLHR YSDKHNCPYD YKAEAAAKIR KANRCHMCKK RVGLTGESCR CGGLYCGDHR YDQAHNCQFD YKTMERETIR k.NRC.MCkK kVGLTGF.CR CGgL $\%$ G.HR Yd.aH\#C. $\%$ Ykt.ere.Ir

$$
2012214
$$

KNNPTIGFNK IERI

KENPVVVAEK IQRI

KENPVVVAEK IQRI

KNNPVVVSDK VQRI

K\#NPV!V.\#R ! \#RI 
limited success. These assays include skin testing with larval extracts, indirect immunofluorescence using fixed larvae, radioallergosorbent testing for specific IgE and gelatin particle agglutination (for review see, Liu \& Weller, 1993; Grove, 1996). An ELISA for detecting the serum IgG against a crude extract of the filariform larvae of $S$. stercoralis is also available (for review see, Liu \& Weller, 1993; Grove, 1996). The sensitivity and specificity of this ELISA can be improved to about $85 \%$ if the serum samples are preincubated with Onchocerca antigens before testing (for review see, Gam et al., 1987; Genta, 1989; Liu \& Weller, 1993; Conway et al., 1994; Grove, 1996). The ELISA is available only at specialized centers and a very limited number of clinical diagnostic laboratories. Furthermore this ELISA shows extensive cross-reactivity with hookworms, filaria, schistosomes, Paragonimus, and Echinococcus; and cannot be used in over $1 / 3$ of the world population which is known to be infected with these parasites (for review see, Liu \& Weller, 1993; Grove, 1996, Siddiqui et al., 2000b). On a practical basis, this test is unlikely to be available for a wider use because a constant supply of the S. stercoralis larval tissue is needed to obtain the crude antigen preparation and abundant supply of Onchocerca antigens is also required for presoaking of sera samples, before performing an ELISA detection test.

A rational way to develop a detection system for S. stercoralis is to first identify highly specific and immunoreactive antigens of the parasite and then exploit their immunodiagnostic potential (Siddiqui et al., 1997, 2000b; Ramachandran et al., 1998). SsZFP may turn out to be an important antigen for diagnostic purposes because it is highly immunoreactive, however, we have not yet exhaustively studied its cross-reactivity with other helminth infections. We are now generating recombinant SsZFP to study its specificity for S. stercoralis.

\section{REFERENCES}

Altschul F., Madden T.L., Schäffer A.A., Zhang J., Zheng Z., Miller W. \& LipMAN D.J. Gapped BLAST and PSIBLAST: a new generation of protein database search programs. Nucleic Acids Research, 1997, 25, 3389-3402.

Berk S.L., Verghese A., Alvarez S., Hall K. \& Smith B. Clinical and epidemiological features of strongyloidiasis: a prospective study in rural Tennessee. Archives of Internal Medecine, 1987, 147, 1257-1261.

Blackwell T.K., Bowerman B., Priess J.R. \& Weintraub H. Formation of a monomeric DNA binding domain by Skn-1 by ZIP and homeodomain elements. Science, 1994, 266, 621-628

Conway D.J., Lindo J.F., Robinson R.D., Bundy D.A. \& Bianco A.E. Strongyloides stercoralis: characterization of immu- nodiagnostic larval antigens. Experimental Parasitology, 1994, 79, 99-105.

CORPET F. Multiple sequence alignment with hierarchial clustering. Nucleic Acids Research, 1988, 16, 10881-10890.

Gam A.A., Neva F.A. \& Krotoski W.A. Comparative sensitivity and specificity of ELISA and IHA for serodiagnosis of strongyloidiasis with larval antigens. American Journal of Tropical Medicine and Hygiene, 1987, 37, 157-161.

GENTA R.M. Global prevalence of strongyloidiasis: critical review with epidemiologic insights into the prevention of disseminated disease. Reviews of Infectious Diseases, 1989, 11, $755-767$.

Grove D.I. Human strongyloidiasis. Advances in Parasitology, 1996, 38, 251-309.

Karcz S.R., Podesta R.B., Siddiqui A.A., Dekaban G.A., Strejan G.H. \& ClARKE M.W. Molecular cloning and sequence analysis of a calciumactivated neutral protease (calpain) from Schistosoma mansoni. Molecular and Biochemical Parasitology, 1991, 49, 333-336.

Linnen J.M., Bailey C.P.\& Weeks D.L. Two related localized mRNAs from Xenopus laevis encode ubiquitin-like fusion proteins. Gene, 1993, 128, 181-188.

LIU L.X. \& Weller P.F. Strongyloidiasis and other intestinal nematode infections. Infectious Disease Clinics of North America, 1993, 7, 655-682.

Mansfield L.S., Niamatali S., Bhopale V., Volk S., Smith G., LOK J.B., GENTA R.M.\& SCHAD G.A. Strongyloides stercoralis: maintenance of exceedingly chronic infections. American Journal of Tropical Medicine and Hygiene, 1996, 55, 617624.

Moore T.A., Ramachandran S., Gam A.A., Neva F.A., Lu W., SANDERS L., Williams S.A. \& Nutman T.B. Identification of novel sequences and codon usage in Strongyloides stercoralis. Molecular and Biochemical Parasitology, 1996, 79, 243-248.

Neva F.A., Gam A.A. \& Burke J. Comparison of larval antigens in an enzymelinked immunosorbent assay for strongyloidiasis in humans. Journal of Infectious Diseases, 1981, 144, 427-432.

Quandt K.F., Kayas H., Wingender E. \& Werner T. New fast and versatile tools for detection of consensus matches in nucleotide sequence data. Nucleic Acid Research, 1995, 23, 4875-4884.

Ramachandran S., Thompson R.W., Gam A.A. \& Neva F.A. Recombinant cDNA clones for immunodiagnosis of strongyloidiasis. Journal of Infectious Diseases, 1998, 177, 196203

REINHARDT A. \& HUBBARD T. Using neural networks for prediction of the subcellular location of proteins. Nucleic Acids Research, 1998, 26, 2230-2236.

Sato Y., Kobayashi J.\& Shiroma Y. Serodiagnosis of strongyloidiasis. The application and significance. Rev. Inst. Med. Trop. Sao. Paulo, 1995, 37, 35-41.

Scott D.A., Greinwald J.H. Jr, Marietta J.R., Drury S., SwiderSki R.E., Vinas A., Deangelis M.M., Carmi R., Ramesh A., Kraft M.L., Elbedour K., Skworak A.B., Friedman R.A., Srikumari Srisailapathy C.R., Verhoeven K., Van Gamp G., 
Lovett M., Deininger P.L., Batzer M.A., Morton C.C., Keats B.J., Smith R.J. \& ShefField V.C. Identification and mutation analysis of a cochlear-expressed, zinc finger protein gene at the DFNB7/11 and dn hearingloss loci on human chromosome 9q and mouse chromosome 19. Gene, 1998, 215, 461-469.

Siddiqui A.A., Koenig N.M., Sinensky M.\& Berk S.L. Strongyloides stercoralis: identification of antigens in natural human infections from endemic areas of the United States. Parasitology Research, 1997, 83, 655-658.

Siddiqui A.A, Stanley C.S, Skelly P.J \& Berk S.L. A cDNA encoding a nuclear hormone receptor of the steroid-thyroid hormone-receptor superfamily from the human parasitic nematode Strongyloides stercoralis. Parasitology Research, 2000a, 86, 24-29.

Siddiqui A.A, Stanley C.S \& Berk S.L. A cDNA encoding the highly immunodominant antigen of Strongyloides stercoralis: $\gamma$-subunit of isocitrate dehydrogenase $\left(\mathrm{NAD}^{+}\right)$. Parasitology Research, 2000b, 86, 279-283.

Siddiqui A.A, Stanley C.S \& Berk S.L. Cloning and expression of isocitrate lyase from human roundworm Strongyloides stercoralis. Parasite, 2000c, 7, 233-236.

Walker A.K., See R., Batchelder C., Kophengnavong T., Gronniger J.T., Shi Y. \& Blackwell T.K. A conserved transcription motif suggesting functional parallels between Caenorhabditis elegans SKN1 and Cap'n'Collarrelated basic leucine zipper proteins. J. Biol. Chem., 2000, 275, 2216622171

WeHner J.H. \& Kirsch C.M. Pulmonary manifestations of strongyloidiasis. Semin. Respiratory Infections, 1997, 12, 122-129.

Woodring J.H., Halfhill H.N.D., Berger R., Reed J.C. \& Moser N. Clinical and imaging features of pulmonary strongyloidiasis. Southern Medical Journal, 1996, 89, 1019.

Zaha O., Hirata T., Kinjo F. \& Saito A. Strongyloidiasis: progress in diagnosis and treatment. Internal Medicine, 2000, 39, 695-700.

Reçu le 16 octobre 2000 Accepté le 26 mars 2001 